\title{
Effects of warming depend on germination strategies and developmental stage in the alpine herb Oreomyrrhis eriopoda
}

\author{
Annisa Satyanti ${ }^{1}$, Toton Liantoro ${ }^{1}$, Morgan Thomas $^{1}$, Teresa Neeman ${ }^{1}$, Adrienne Nicotra ${ }^{1}$, \\ and Lydia Guja ${ }^{2}$ \\ ${ }^{1}$ Australian National University \\ ${ }^{2} \mathrm{CSIRO}$
}

July 7,2020

\begin{abstract}
Global warming is already affecting plant phenology, growth and reproduction. A wide range of evidence indicates warming effects on reproductive and vegetative traits, as well as phenology, but seldom do studies assess these traits in concert and across the whole of a plant's life cycle, particularly in wild species. Further, while there is evidence that these effects vary between species little is known about the extent of within-species variation for plant persistence under future warming scenarios. We assessed trait variation in response to warming in Oreomyrrhis eriopoda, an Australian native montane herb, in which withinspecies variation in germination strategy and growth characteristics has been demonstrated. We quantified associations between developmental trajectories and population-level variation in germination timing and examined whether the next-generation traits are altered by maternal growth conditions. Warming effects were expressed in different traits during different developmental stages. The effect of warming varied as a function of germination strategy, but germination strategy itself was conserved across generations. Thus, we conclude that understand the response of wild species to warming takes a whole-of-life perspective and attention to ecologically significant patterns of within species variation.
\end{abstract}

\section{Key-words}

Germination temperature, intraspecific trait variation, maternal effects, seed development temperature, germination plasticity, transgenerational effects, phenotypic plasticity

\section{ACKNOWLEDGEMENTS}

We thank the Plant Services team and the workshop of the Australian National University for expertly facilitating our work in the glasshouses. Abby Ryan, Tobias Hayashi, Sonya Geange, and Niccy Aitken for helping establish the experiment, The National Seed Bank Australian National Botanic Gardens seed volunteers for cleaning the seeds. Annisa Satyanti was supported by an Australian Government Research Training Program (RTP) Scholarship.

\section{INTRODUCTION}

Addressing the impact of global warming on plants requires an understanding of multiple traits across plant life stages, not only within but also across generations. Warming, as associated with climate change, has 
a strong effect on phenotypic traits throughout a plant's life cycle. Warmer temperatures generally lead to increased biomass and vegetative growth (Debouk, de Bello, \& Sebastià, 2015; King, Pregitzer, \& Zak, 1999; Lin, Xia, \& Wan, 2010; Walker et al., 2006), reduced flower numbers and seed production (Hedhly, Hormaza, \& Herrero, 2009; Liu, Mu, Niklas, Li, \& Sun, 2012), increased mortality at both seedling and adult stages (Allen et al., 2010; Hovenden et al., 2008; Milbau, Vandeplas, Kockelbergh, \& Nijs, 2017), delays and decreases in seedling emergence (Cochrane, Hoyle, Yates, Wood, \& Nicotra, 2015), and potentially can lead to local extirpation of the species (Panetta, Stanton, \& Harte, 2018). Phenology, the timing of biological events - e.g. bud burst, flowering, seed set, and senescence - is thought to be the characteristic that is most sensitive to warming and hence, most observations of responses to climate change have focused on shifts in phenology (Arft et al., 1999; Cadman, Toorop, Hilhorst, \& Finch-Savage, 2006; Cleland, Chuine, Menzel, Mooney, \& Schwartz, 2007; Farnsworth, Nunez-Farfan, Careaga, \& Bazzaz, 1995; Jin et al., 2011; Körner \& Basler, 2010; Menzel et al., 2006; Moore \& Lauenroth, 2017; Munson \& Sher, 2015; Peñuelas \& Filella, 2001; Rathcke \& Lacey, 1985; Root et al., 2003; Sherry et al., 2007; Walther et al., 2002).

Warming responses of vegetative growth, reproductive output and phenological traits (including senescence) should not, however, be viewed in isolation (Hoffmann \& Sgrò, 2011; Leblans et al., 2017; Merilä \& Hendry, 2014; Nicotra et al., 2010). Rather, variation in trait values and timing of phenological events determines subsequent interactions of the individual with the environment and because of this co-dependence, the responses to environmental change are likely to be quite complex. For example, germination timing (spring versus autumn) determines the seasonal conditions and duration of seedling exposure as well as the conditions in which subsequent life stages occur. Accordingly, germination timing determines conditions at flowering time, reproductive period and lifespan in annuals (Donohue, 2009; Lu, Tan, Baskin, \& Baskin, 2016). Time to flowering, likewise, could determine the season of seed maturity with implications for germination timing, and the germination timing could in turn determine whether the offspring will become annual or biennial (Galloway, 2005; Galloway \& Etterson, 2007). Thus, a shift in the timing of one phenological event can have cascading effects for the subsequent life events. However, these shifts do not necessarily all occur in concert, for example, early flowering in response to warming is not always followed by a change in timing of cessation of flowering and thus may result in the expansion or contraction of the flowering period (CaraDonna, Iler, \& Inouye, 2014).

Warming effects may also be highly species- or even population-specific. For example, prairie species that have early-flowering (spring to mid-summer) start to flower even earlier, and conversely, late-flowering species (mid-summer to autumn), delay their flowering when exposed to warming treatments (Dunnell \& Travers, 2011; Sherry et al., 2007). In the sub-arctic herb Cerastium fontanum, plants from warmer microsites (populations) flower earlier than those from colder microsites but when grown in much warmer common gardens, plants from warmer microsites start to flower later than plants originating from colder microsites (Valdés, Marteinsdóttir, \& Ehrlén, 2019). In the alpine herb Aciphylla glacialis, seedlings growing under an open top chamber exhibit higher mortality (but surviving individuals grow faster) than those under ambient conditions (Geange, Holloway-Phillips, Briceño, \& Nicotra, 2020), regardless of the population source (Briceño, HarrisPascal, Nicotra, Williams, \& Ball, 2014). Species response to warming may also be dictated by functional traits. Between geographically co-occurring species, the seedlings of fast-growingBanksia coccinea, characterized by higher SLA (specific leaf area) and leaf growth rate, can maintain growth at high temperatures better than its slow-growing congeneric B. baxteri (Cochrane, Hoyle, et al., 2015). Within a plant's life cycle, response to elevated temperatures can also be trait-specific. For example, inArabidopsis thaliana warming advances flowering time, accelerates vegetative development and fruit production but not plant mortality (Springate \& Kover, 2014). So far, the studies on plant responses to climate change often focus only on particular suites of traits (e.g. leaf traits or flowering phenology) and only at a certain life stage (mostly adult reproductive), which may lead to incomplete assessments and failure to predict the cascading effects of warming on species' persistence, and thus community composition and ecosystem functions and services.

While research on the adaptive capacity of plants under future climate is increasing, we still lack understanding of plant plasticity and their capacity to evolve when challenged by new environmental conditions, especially for germination and the seedling stage (Parmesan \& Hanley, 2015). Studies across ontogeny that 
span whole life events, and multiple generations, are also lacking. Maternal conditions may have carry-over effects across generations and could determine the life history of the progeny (Donohue, 1998; Donohue, 2009). When these maternal effects increase offspring fitness, this trans-generational plasticity may be adaptive (Galloway, 2001a, 2001b, 2005; Galloway \& Etterson, 2007; Herman \& Sultan, 2011). For example, warmer temperatures during seed development generally reduce the degree of primary seed dormancy (Bernareggi, Carbognani, Mondoni, \& Petraglia, 2016; Gutterman, 2000; Hoyle, Steadman, Daws, \& Adkins, 2008; Huang, Footitt, Tang, \& Finch-Savage, 2018), enabling individuals to start growing and to reach reproductive stage earlier in the season and thus have a longer duration for seed production and potentially produce more seeds (Donohue, de Casas, Burghardt, Kovach, \& Willis, 2010; Roach \& Wulff, 1987). Climate induced variation in seed dormancy status, in turn, may play shift timing of germination or variance therein, providing a buffer against disturbances that may be a bet-hedging strategy. Changes in dormancy may also affect seedling growth rate and establishment (Satyanti, Guja, \& Nicotra, 2019), or physiological traits such as water use efficiency, reproductive phenology and senescence (Kimball, Angert, Huxman, \& Venable, 2010, 2011). Understanding the extent to which germination strategy, particularly the degree of dormancy and how it is lost over time, could change with warming and whether maternal temperature interacts with offspring germination requirements to affect germination success will be valuable for predicting species persistence in the face of a changing climate.

Alpine regions are recognized as one of the most vulnerable ecosystems under warming climates - impacts are forecast to be pronounced and detectable earlier than in other biomes (Grabherr, Gottfried, \& Pauli, 2010). Alpine plants that are adapted to low temperature and a short growing season are particularly responsive to warming (Anadon-Rosell et al., 2014; Arft et al., 1999; Bjorkman, Elmendorf, Beamish, Vellend, \& Henry, 2015; Cao et al., 2016; Geange et al., 2017; Geange et al., 2020; Kudernatsch, Fischer, BernhardtRömermann, \& Abs, 2008; Kudo \& Suzuki, 2003; Oberbauer et al., 2013). Perhaps paradoxically, seeds of alpine plants generally require relatively high soil temperature to trigger germination (Hoyle et al., 2013; Schütz, 2000; Schütz \& Milberg, 1997) and hence, warming could have a positive effect on recruitment via seed. In strongly seasonal and unpredictable environments, plants often evolve specific seed dormancy that leads to divergence in germination strategy (Hoyle et al., 2015; Satyanti et al., 2019; Willis et al., 2014). Variation of germination strategy across alpine species is common (Hoyle et al., 2015; Körner, 2003; Satyanti, 2018), but more strikingly, intraspecific variation in germination strategy with environment and elevation is also documented (e.g. Hoyle et al., 2015; Satyanti et al., 2019; Vidigal et al., 2016; Wagner \& Simons, 2009). Such variation in germination strategy may help to facilitate the regeneration and survival of plants in short growing seasons, and highly variable environments, as reported from (Satyanti et al., 2019).

Oreomyrrhis eriopoda (Apiaceae) is a native rosette-forming herb from the Australian Alps that exhibits has four germination strategies: immediate, staggered, postponed, and postponed-deep (Satyanti et al., 2019). Populations with an immediate strategy produce non-dormant seed and thus "autumn seedlings". Populations that produce dormant seeds (postponed strategy) produce "spring seedlings". Populations categorised as postponed-deep germinate (usually in spring) after exposure to multiple cycles of winter conditions. Populations that exhibit the staggered strategy produce both non-dormant and postponed seeds in the same accession and thus both "autumn" and "spring seedlings" occur (e.g. Hoyle et al., 2015; Satyanti et al., 2019). The among-population variation in germination strategy in $O$. eriopodaleads to substantial differentiation of seedling growth among and within populations (in staggered populations autumn seedlings grow faster than spring seedlings) (Satyanti et al., 2019).

So far, we know little about the extent of intraspecific germination strategy variation in plant responses to warming. Particularly, to what extent plants are able to increase growth rate and to adjust phenology to maximise reproductive capacity and fitness. Using O. eriopoda, we aim to understand the effect of warming across all life stages (vegetative growth, reproductive output, phenology and the germination traits of the seed produced), and to explore whether populations of different germination strategies show variation in those warming responses in the current and subsequent generation. We hypothesised that: (i) Warming would interact with germination strategies and overall would enhance growth at the cost of flower and fruit production, and likely with an increase in plant mortality; (ii) Plant responses to soil temperature would 
depend on germination strategy; (iii) Germination strategy of the offspring will be affected by warming of the maternal environment.

\section{MATERIALS AND METHODS}

\section{Propagation}

Accessions (population level seed samples) of O. eriopoda were sourced from the National Seed Bank of the Australian National Botanic Gardens Canberra, The Australian Botanic Gardens Mount Annan, The Royal Tasmanian Botanical Gardens, and Royal Botanic Gardens Victoria and germinated as described in Satyanti et al. (2019). We included seedlings from 16 populations (Figure S1 and Table S1) that represented the range of germination strategies expressed in this species. We aimed for a balanced representation of germination strategies based on early assay results, however there were many populations with postponed germination so we included more of those to be representative. Consequently, we had three populations with an immediate germination strategy, three with a staggered strategy, seven postponed and three with a postponed-deep germination strategy (Table S1). Seeds from each population were germinated in two batches so that germination of early (autumn) and late (spring) seedlings coincided and seedling age was consistent regardless of germination strategy (Appendix S1). This design addressed the potentially confounding factors of age, size and starting time of the experiment and allowed us to manage these factors within the logistical constraints of a blocked design (Lu et al., 2016). Seeds germinating on agar were transplanted within 1-2 weeks to soil media in pots and grown under temperatures conducive to growth. Seedlings were grown until they were $18-20$ weeks old when they had $8 \pm 3.6$ (SD) leaves and we inferred that the establishment stage was complete (Appendix S1). As O. eriopoda is slow growing, this establishment step was important to ensure that plants across all populations were large enough to withstand transplant stress and thus to avoid confounding soil warming effects.

\section{Experimental design}

Soil temperatures are particularly important for alpine species because given their low stature, soil temperatures determine the microclimate to which plants are exposed more than the air temperatures do (Körner, 2003; Reinhardt \& Odland, 2012; Scherrer, Schmid, \& Körner, 2011; Wolkovich et al., 2012). We therefore focused our study on the effect of soil warming on plant traits.

For each population, ten individuals were randomly allocated to each of the two soil warming treatments. We assessed initial seedling size and confirmed that there were no a-priori differences in the size of plants between ambient and warm soil treatments (linear mixed model with germination strategy as a random term; $p=0.286$ and 0.52 for leaf number and leaf length, respectively). For the staggered germination strategy, both early (autumn) and late (spring) seedlings, were placed in the respective block, thus, these populations had 20 individuals/soil warming treatments. One representative population of each putative germination strategy was assigned to each of the four blocks. The imbalance of populations for each germination strategy was not an impediment for the analyses. There were five populations for which we did not have 20 seedlings and for these we assigned half of the available number to each warming temperature. Extra plants were placed in the empty spaces on the bench to maintain homogeneous spacing across the experiment but were not included in analyses (number in grey, Figure S1).

Warm and ambient benches were set up in a glasshouse with air temperature set to follow the seasonal changes and natural photoperiod (Fig. S2). The targeted air temperature day/night sequence was $20 / 10^{\circ} \mathrm{C}$ (autumn), $5 / 5{ }^{\circ} \mathrm{C}$ (winter), $20 / 10{ }^{\circ} \mathrm{C}$ (spring), $25 / 15{ }^{\circ} \mathrm{C}$ (summer), and finally $20 / 10{ }^{\circ} \mathrm{C}$ (autumn). Soil warming was achieved by placing a heating mat (Electronic Foil Panel with Thermostat, ADLOHEAT, Victoria) on a given bench set to be continuously $\sim 5{ }^{\circ} \mathrm{C}$ warmer than the set glasshouse air temperature throughout the experimental period, including winter. The $5{ }^{\circ} \mathrm{C}$ soil temperature increase is based on Australian alpine mean 
air temperature predictions for 2050, i.e. an increase of +0.6 to $+2.9{ }^{\circ} \mathrm{C}$ (Hennessy et al., 2003) and that the maximum soil temperatures in Australia are to increase by almost double that of air temperature by the end of 21st century (Ooi, Auld, \& Denham, 2009). The $5{ }^{\circ} \mathrm{C}$, thus, falls between the predicted +1.2 to 5.8 ${ }^{\circ} \mathrm{C}$ soil temperature increase by 2050 . The ambient treatment was located on benches that had mats but no heat, paired one each with the four heated benches. A frame of $6 \mathrm{~mm}$-thick PVC sheet was placed around each bench, $17 \mathrm{~cm}$ above the mat, and a $5 \mathrm{~cm}$ thick sheet of polystyrene foam was placed on the top of this to insulate the soil. Square openings in the polystyrene matched the pot size and held these in place in the frame. Temperature at plant level (15 cm above bench; Fig. 1) and soil (2,8 and $14 \mathrm{~cm}$ below surface) was monitored during the course of the experiment with i-Button data-loggers (Thermochron DS1921G, Temperature Technology, Adelaide) in each block (32 in total, Fig 1). We analysed the temperatures at plant and soil level to determine efficacy of the design using ANOVA and found significant warming differences for each of the soil and air depths/height. The temperature difference between ambient and warm soil at 8 -cm below the surface (where most roots were located) was approximately $6{ }^{\circ} \mathrm{C}$ during the day and $9{ }^{\circ} \mathrm{C}$ during the night (Fig. 1), in agreement with climate patterns which show that night-time temperatures have increased more than day-time temperatures (Donat \& Alexander, 2012; Easterling et al., 1997). With warmer air temperature and reduced snow cover, the soil in the Australian Alps becomes warmer, evidenced by a snow removal experiment (Slatyer, 2016). Thus, we also increased the soil temperature during winter for the warmer soil scenario. In summer soil was warmed to $\sim 35{ }^{\circ} \mathrm{C}$ which is realistic for the Australian mountains where bare dark soils can easily exceed $45{ }^{\circ} \mathrm{C}$ on sunny days and the difference to the nearby vegetated soils can be over $30{ }^{\circ} \mathrm{C}$ (Slatyer, 2016).

The irrigation system was set to keep plants adequately-watered. We used an automatic Water-Pro vapour pressure deficit (VPD) to provide an automatic watering system (MicroGrow Green House Systems, Temecula, California), with each plant being watered individually by a dripper at soil level. Drippers were calibrated to a standard flow rate that was checked at the beginning of the experiment. Watering events were triggered when pre-set VPD targets were reached. Plants received $90 \mathrm{ml}$ per watering which was enough to saturate the soil at the start of the experiment. As the plants grew, we adjusted the VPD point, based on the two sensors for ambient and warm soils, so that the drippers delivered water sufficiently more frequently to the plants in the warmed treatment to keep all plants healthy.

\section{Trait measurement}

Leaf number and the length of the longest leaf were recorded for all plants at the start of the experiment, and at the end of autumn (day 38). Those traits were recorded for a subset of plants (4 individuals per soil temperature and population) in early spring (day 124). Leaf increment rate at the early vegetative stage was calculated from the difference of leaf number at the end of autumn from the start divided by 38 (number of days from planting). Leaf increment at the transition to reproductive stage was the difference between total leaf number at day 38 and day 124, divided by 86 (number of days between measurement).

Specific Leaf Area (SLA) is an indicator of resource allocation and ecological strategy. We expected that plants growing faster in warmed conditions would have higher SLA. SLA was measured for every individual at the start of winter (day 52). SLA was measured by acquiring the youngest fully expanded leaf for each individual. The leaf was then scanned on a flatbed scanner, dried at $60{ }^{\circ} \mathrm{C}$ for $72 \mathrm{hrs}$ and weighed. The SLA was calculated as area/weight $\left(\mathrm{cm}^{2} \mathrm{~g}^{-1}\right)$.

In early spring, a random sample (four plants, even numbered individuals, per population per soil treatment) was photographed with a reference scale over a white Styrofoam board to determine total canopy area. Each plant image was then converted to an 8-bit graphic file. The threshold was adjusted so that only the actual canopy area was detected for selection and using the known distance of the reference scale we calculated the plant area. The image analysis of the canopy area was performed in ImageJ (Schneider, Rasband, \& Eliceiri, 2012).

Plants were monitored every $1-2$ days for phenology. The date at which the first inflorescence with closed 
buds emerged from the plant base was recorded as first flowering. All infructescences were collected at the point of natural seed dispersal when all seeds were brown or purple-brown and easily dislodged, and the date of collection was recorded for each infructescence. Infructescences were stored at $15 \% \mathrm{RH}$ and $15{ }^{\circ} \mathrm{C}$. Total number of inflorescences and infructescence were determined for each plant. Further, we measured individual seed mass for five, even numbered, individuals per population per soil treatment by weighing three replicates of 25 seeds (Figure S1). The date of collection of the last infructescence was recorded as the end of seed dispersal, and the time between the first and the last seed harvest was defined as the duration of seed production. Some plants naturally senesced over the course of the experiment and the date of senescence (all leaves browned, no new leaves emerging) was recorded. At the end of the experiment, aboveground biomass was harvested for all plants, dried at $60{ }^{\circ} \mathrm{C}$ to constant weight, and weighed. Plants that died before harvest were sampled for biomass within a week of senescence.

\section{Transgenerational effect on germination traits}

To minimise potential genetic influences that may have occurred from cross-pollination of populations, populations were separated by organza fabric sheeting supported by a plastic frame. Seed was collected from plants at the time of natural dispersal and stored separately at the plant level.

Seeds from parent plants of three germination strategies: immediate, staggered, and postponed were used to test whether there was an effect of soil temperature during development on the germination strategy and response to germination temperature of progeny. Ten populations were selected to represent the three germination strategies, three immediate, three staggered and four postponed strategies (Figure S1). For each population and soil temperature we selected 50 seeds produced in the peak seed production period from each of five fruiting individuals per warming treatment. Twenty-five seeds each were sown on each of two petri dishes, and randomly allocated to one of two germination chambers set at $25 / 15{ }^{\circ} \mathrm{C}$ and $30 / 20{ }^{\circ} \mathrm{C}$ $12 / 12$ hours photoperiod for 9 weeks. Subsequently the seeds were transferred to $5{ }^{\circ} \mathrm{C}$ for 8 weeks and then returned for 17 weeks to the same temperature regimes they were initially allocated to $\left(25 / 15{ }^{\circ} \mathrm{C}\right.$ or $30 / 20$ ${ }^{\circ} \mathrm{C}$ ). Germination was scored weekly as the seeds moved through the temperature regimes (beginning week 1 until week 34), to develop germination curves for each population and warming treatment. At the end of the experiment a cut-test was performed to determine whether ungerminated seeds were empty, dormant, or dead. Each chamber consisted of five blocks (shelves). For a given population, one maternal plant was represented in each block.

\section{Statistical analyses}

Mixed models were selected for the analysis of plant traits. Models included terms for germination strategy and soil temperature and the interaction thereof as fixed factors, and populations, nested within blocks, were assigned as random factors. Some exceptions were made in the random model where either block or population was used as the random factor because inclusion of population nested in block resulted in convergence failure (see Table S2). Vegetative and reproductive traits that were discreet (number of leaves, number of inflorescences, number of inflorescences, day to flower, day to seed dispersal, seeding duration, and day to senesce) were analysed using Generalized Linear Mixed Models (GLMM), setting the distribution family as Poisson and the link function as natural logarithm (Bolker et al., 2009). Leaf number (but not length of the longest leaf) at the start of the experiment significantly varied across germination strategies (Table S2). Hence, we used leaf number at the start of the experiment as a covariate for corresponding traits, i.e. leaf number, leaf increment rate, SLA, plant area, aboveground biomass. For proportion data (survival and proportion of plants producing seed), GLMM were used with the distribution family as binomial, the link function as logit, and the dispersion parameter set to be estimate. Responses that were continuous (longest leaf, leaf increment rate, individual seed mass, SLA, and aboveground biomass) were analysed with Linear Mixed Models (Restricted Maximum Likelihood, REML. Leaf increment rates, plant area, seed mass, and aboveground biomass were log-transformed prior to fitting to REML (Table S2). 
Repeated measures analyses were run for the leaf number and leaf length using germination strategy, soil temperature and measurement time as fixed factors. Population nested in block was used as the random model and leaf number at the start of the experiment as covariates for the analysis of the leaf number. However, the results were the same as when we performed the analyses for each measurement time point and thus, we present the results from the two measurement points as they provide clearer visual inference.

To assess transgenerational effects on germination strategy, we analysed the final germination, non-dormant seed fraction (germination before spring), and time to reach $50 \%$ germination of the F1 seeds. The final germination and non-dormant seed fraction were analysed using GLMM, assigning germination temperature, soil temperature, and germination strategy as the fixed factors, population and individual plants nested on the incubator shelf were set as the random factor, and we set the distribution family as binomial and the link function as logit. Time to reach $50 \%$ germination was derived by examination of cumulative germination for each dish to the closest 0.25 week and treated as a continuous variable and analysed using Linear Mixed Models (REML) with fixed and random factors as for the non-dormant fraction analyses. GLMM and REML were performed in Genstat $19^{\text {th }}$ Edition.

\section{RESULTS}

The effect of warming was pronounced over the course of the $O$. eriopoda life cycle, but patterns of effects varied among traits (Fig. 1). We measured 19 functional traits important to establishment, growth and fitness (Table 1) across three different life history stages (vegetative, reproductive, and transgenerational) and analysed for significant effects of warming, germination strategy, and interactions thereof. Sixteen of the 19 variables showed significant responses, i.e. either the interaction or at least one of the two main variables yielded significant effects (Table 1,2).

\section{Vegetative}

Soil warming significantly increased early vegetative growth for some germination strategies (Table 1). Soil warming significantly increased the number of leaves and the leaf increment (leaf number per day) in the immediate and postponed-deep germination strategies, but not the staggered or postponed strategy (Fig. 2a and $b$ ). Leaf size decreased under warmer conditions only in the immediate germination strategy, while for other strategies leaf number between ambient and warmer soil was constant. SLA differed across strategies and warming increased SLA regardless of the germination strategies (Table 1).

The effect of warming and germination strategies on vegetative growth diminished at the transition from vegetative to reproductive stage when many individuals had just started to flower. Rosette size indicated by the canopy area and leaf number were not affected by warming and germination strategy (Table 1). Interestingly, at the transition to reproductive stage, warming was associated with a reduction instead of an increase in leaf increment regardless of germination strategy - contrary to the response shown during the early vegetative state (Fig. 2, Table 1). Thereby, despite the positive effect of warming on vegetative at the early stage, final aboveground biomass of plants growing under warming treatment was significantly lower than that of ambient plants (Fig. 1, Table 1).

\section{Reproductive output}

The effect of soil warming on reproductive output was generally negative regardless of germination strategy. Warming reduced the number of inflorescences produced and the number of viable infructescences per plant across strategies (Fig. 1, Fig. 3a and 3b, Table 1). Overall, there was also a significant reduction in the total number of plants flowering (Fig. 4, Table 1) under warmed conditions.

Individual seed mass varied among germination strategies with seed of the immediate strategy being lightest and staggered being heaviest, but warming did not result in any change in seed mass (Fig. 1, Fig. 3c, Table 1). Compared to the field collected seed, mass of the seed produced in the soil warming experiment was up to $1.2 \mathrm{mg}$ per seed heavier than the seed collected from the field (parent), except for those exhibiting an immediate germination strategy, where seed mass between field and experiment was constant (Fig. 3c). 


\section{Phenology}

The number of days to first flowering significantly varied with germination strategy and was not affected by soil warming (Fig. 1, Fig. 4, Table 1). Although warming did not affect flowering time, it accelerated time to seed maturity and reduced the overall duration of seed production. Immediate germination strategy plants flowered 50 days earlier and the seeds were relatively slower to mature compared to the three other strategies (Fig. 4, Table 1). Consistent with their early flowering date, absolute timing of seed maturity of immediate strategy was earlier compared to the other strategies (Fig 4, Table 1). Finally, the plants senesced earlier in warmer soil than in ambient soil (Fig. 1, Fig. 4, Table 1). At the end of the experiment a greater proportion of plants survived in the ambient than warmed conditions for all germination strategies except the postponed strategy, in which mortality was approximately $95 \%$ regardless of growth temperature (Fig 4, Table 1).

\section{Transgenerational effects of warming}

Final germination of $\mathrm{F} 1$ seeds across germination strategies and soil temperature treatments was $>90 \%$, indicating that all seeds produced were healthy and viable regardless of maternal soil temperature. Germination temperature in contrast did affect offspring germination (Fig. 3d). Warmer germination temperature led to longer time to reach $50 \%$ germination and reduced germination of the non-dormant seed fraction regardless of the germination strategy and maternal warming (Table 2, Table S3). The absence of an interaction effect between germination temperature and maternal warming indicates that maternal soil temperatures did not affect the response to germination temperatures, such that seeds produced from plants in warm soil did not do better at higher germination temperatures than seeds produced from plants in ambient soil. Across generations, germination strategies were not only conserved across strategies (Fig. 3d), but also within strategy, i.e. plants of staggered strategy produced seeds that had a staggered germination strategy regardless of whether the maternal plant was an autumn or spring germinant (Fig S2). In addition, the proportion of dormant and non-dormant seeds within staggered populations was relatively constant (Fig S2).

\section{DISCUSSION}

This study examined the effect of soil warming on a whole-of-life array of traits (vegetative growth, reproductive output and phenological response traits including senescence), as well as the germination traits of the next generation, for populations of $O$. eriopoda with four different germination strategies. Our findings suggested that responses to soil warming and germination strategy are complex, indeed not as straightforward as we hypothised. In many instances, the responses were trait-specific. Since we followed the whole life cycle, we were able to observe that the effect of soil warming on traits changed through ontogeny and was mostly apparent in the respective active growth stages of the plant life cycle, demonstrating that care must be taken in extrapolating from responses of a given trait at any point in time to a whole-of-life conclusion. We also confirmed that the pattern and direction of warming effects varied depending on the germination strategy of the populations of $O$. eriopoda in question. We consider the diversity of these responses to warming throughout the life cycle, and among germination strategies within a species, to be extraordinary as they highlight the complexity of linkages between the maternal and offspring environment and make evident that without a whole-of-life perspective we will struggle to predict impacts of global change on species. Here we interpret these elements in the context of impacts of warming on persistence of $O$. eriopoda and other alpine species in a novel future climate.

Under rapid climate change, plasticity in phenology and reproductive traits is likely to have strong fitness consequences (Kozłowski, 1992; Stinson, 2004), and it is possible that different germination strategies will have different selective advantages (Hoyle, Cordiner, Good, \& Nicotra, 2014; Willis et al., 2014). We found that variation in reproductive phenology (Fig. 4) and seed mass (Fig. 3) were inherent to the germination strategy, whereas adult vegetative traits and reproductive outputs were more strongly affected by warming than germination strategy. The ability of this species to adjust reproductive phenology by shortening seed maturation while maintaining seed quality (seed mass) may be advantageous for persistence under in changing climate (Bonser, 2013; Visser \& Both, 2005; Willis, Ruhfel, Primack, Miller-Rushing, \& Davis, 2008); even 
if the total seed number is reduced the seed are spread through the season. Although warming substantially reduced lifespan, it was apparent that $O$. eriopodaindividuals could complete their life cycle and produce healthy, full-size seed with adequate reserves for early establishment success. Nearly all of the seeds produced were viable regardless of germination temperature, maternal conditions, or germination strategy indicating potential to maintain population regeneration.

The interactions of soil warming and germination strategy were mainly evident for seedlings or early vegetative traits and not vegetative traits during the transition to reproductive stage; this corroborates the finding of a previous study by Hoyle et al. (2015) that germination strategy of Australian alpine plants does not correlate with adult vegetative traits. In particular, populations of the immediate germination strategy (mainly occupy lower $<1520 \mathrm{~m}$ elevation sites) exhibited greater plasticity in early leaf increment in response to warming compared to the staggered, postponed, and postponed deep strategies (elevations ranging from $1600 \mathrm{~m}$ to $2200 \mathrm{~m}$, Supplement Table 1). Previous research on Wahlenbergia ceracea, an alpine herb that shares the same habitat with O. eriopoda, also found individuals from higher elevations were less plastic and less likely to express adaptive plasticity in growth-response to warming (Nicotra et al., 2015). The positive response of $O$. eriopoda vegetative traits to warming that was mainly pronounced during earlier ontogeny, however, did not lead to greater growth accumulation and earlier reproductive timing (flowering). The results indicate that there might be an internal constraint for vegetative growth and maintenance (Starr, Oberbauer, \& Pop, 2000) and thus individuals with an immediate germination strategy grew and reached the reproductive stage more quickly but also died earlier than individuals displaying the other strategies.

By germinating the seeds produced in the warming experiment we confirmed that the source of variation in timing of germination in the staggered populations lies within individual plants, indicating a potential bet-hedging strategy (Starrfelt \& Kokko, 2012), which has not been verified in this species before (Hoyle et al., 2015; Satyanti et al., 2019). Interestingly, individual plants produced both non-dormant and dormant seed of varying proportions (Figure S3). This leads to asynchronous germination within the population, and can reduce the risk against recruitment failure (Brown \& Venable, 1986; Simons Andrew, 2009; Stevens, Seal, Archibald, \& Bond, 2014; Venable \& Lawlor, 1980). Should variation in snowmelt patterns compromise recruitment in either season, populations with a staggered strategy could be advantaged and this raises a question about how germination strategy is established and controlled in the species; its high variability indicates it is highly labile on some timeframe.

We examined the transgenerational effect of different seed development (maternal) conditions on germination traits since this has been proposed as a mechanism that may help species to tolerate future climates (Herman \& Sultan, 2011). Given how variable germination strategy is we hypothesized that it may be highly plastic and reflect developmental conditions. But, contrary to expectation, we found no evidence of phenotypic plasticity in seed dormancy, i.e. germination strategy across $O$. eriopoda populations was constant regardless of seed development temperature. The warming impact was imposed when the plants were 18-20 weeks old, not the earliest seedling stage, but given that warming was imposed before the transition to reproductive meristems, this delay seems unlikely to have impeded the response. Our results suggest that seed dormancy variation is not dependent on seed maturation environment. Seed development temperatures have been shown to control seed dormancy induction and cycling in other species (Bernareggi et al., 2016; Donohue et al., 2005; Footitt \& Finch-Savage, 2017; Steadman, Ellery, Chapman, Moore, \& Turner, 2004) but we do not know the relative contributions of air or soil temperature. Further, the degree of seed dormancy, the important determinant of germination strategy, and dormancy cycling may indeed depend on the variation not just the mean of temperature (Satyanti et al., 2019; Topham et al., 2017).

Alternatively, it may be the case that germination strategy is plastic but has a 'half-life'. It is possible that more than one cycle of warming is required to change the dormancy degree or fraction of non-dormant seed of the respective population. Previous studies suggest that the warming effects on seed dormancy and germination traits may be gradual rather than instant, just like phenological trait responses to warming (Franks, Sim, \& Weis, 2007; Hoffmann et al., 2010). Such a delay effect may indicate that the mechanism underlying this shift is epigenetic. Dormancy patterns have been shown to be under epigenetic control in 
other systems (Nonogaki, 2017; Richards et al., 2017), but further research would be needed to demonstrate that here.

Diversification of germination strategies across population,s as exhibited by $O$. eriopoda, could still be an advantage that assists species' persistence (Cochrane, Yates, Hoyle, \& Nicotra, 2015). The potential for plants to respond to warming not only plastically but also as a function of genetic (or epigenetic) variation within the species demonstrates that species' response to warming will often be manifested as a combination of rapid plastic responses and long-term evolutionary responses (Valdés et al., 2019). Considering the spatial and temporal heterogeneity of the alpine environment it is intuitive to expect variations in seed trait, particularly in dormancy, and hence we suggest that variation in germination phenology may be quite common within alpine species (Venable \& Brown, 1988). However, very few studies have documented intraspecific variations in seed dormancy and germination strategy at the level exhibited by O. eriopoda (from populations with non-dormant, dormant, to deeply dormant seeds) and hence, we could not really conclude whether other alpine species would be as resilient under future warming.

An important implication of the results of our study is that predicting species' responses and fate under global warming as either positive, negative or neutral could be a gross oversimplification when such assessments consider only one or few populations or are based only on a limited number of life-stages or traits (Saatkamp et al., 2018). The effects of warming vary not only among populations and individuals but as a function of ontogeny and hence, when assessing response to climate change at both species and community levels, withinspecies variations in germination strategy should be considered as important as between-species variation, and impacts must be assessed on a whole-of-life scale, not just at a single life stage. Our results imply that variability in seed dormancy and germination strategy could be key to assisting a species to persist under unpredictable conditions. Thus, further studies on how common these extraordinary intraspecific variations in seed and germination traits are across species, and the source of variation among individuals, are fundamental to predict the risk of species' survival in a warmer world.

\section{REFERENCES}

Allen, C. D., Macalady, A. K., Chenchouni, H., Bachelet, D., McDowell, N., Vennetier, M., . . Cobb, N. (2010). A global overview of drought and heat-induced tree mortality reveals emerging climate change risks for forests. Forest Ecology and Management, 259 (4), 660-684. doi:https://doi.org/10.1016/j.foreco.2009.09.001

Anadon-Rosell, A., Rixen, C., Cherubini, P., Wipf, S., Hagedorn, F., \& Dawes, M. A. (2014). Growth and phenology of three dwarf shrub species in a six-year soil warming experiment at the alpine treeline. PLOS ONE, 9 (6). doi:http://dx.doi.org/10.1371/journal.pone.0100577

Arft, A., Walker, M., Gurevitch, J., Alatalo, J., Bret-Harte, M., Dale, M., . . Jones, M. (1999). Responses of tundra plants to experimental warming: Meta-analysis of the international tundra experiment.Ecological Monographs, 69 (4), 491-511.

Bernareggi, G., Carbognani, M., Mondoni, A., \& Petraglia, A. (2016). Seed dormancy and germination changes of snowbed species under climate warming: The role of pre- and post-dispersal temperatures. Annals of Botany, 118 (3), 529-539. doi:10.1093/aob/mcw125

Bjorkman, A. D., Elmendorf, S. C., Beamish, A. L., Vellend, M., \& Henry, G. H. (2015). Contrasting effects of warming and increased snowfall on Arctic tundra plant phenology over the past two decades. Global Change Biology, 21 (12), 4651-4661.

Bolker, B. M., Brooks, M. E., Clark, C. J., Geange, S. W., Poulsen, J. R., Stevens, M. H. H., \& White, J.-S. S. (2009). Generalized linear mixed models: A practical guide for ecology and evolution. Trends in Ecology E Evolution, 24 (3), 127-135. doi:10.1016/j.tree.2008.10.008 
Bonser, S. P. (2013). High reproductive efficiency as an adaptive strategy in competitive environments. Functional Ecology, 27 (4), 876-885. doi:10.1111/1365-2435.12064

Briceno, V. F., Harris-Pascal, D., Nicotra, A. B., Williams, E., \& Ball, M. C. (2014). Variation in snow cover drives differences in frost resistance in seedlings of the alpine herb Aciphylla glacialis.Environmental and Experimental Botany, 106 , 174-181. doi:https://doi.org/10.1016/j.envexpbot.2014.02.011

Brown, J. S., \& Venable, D. L. (1986). Evolutionary Ecology of Seed-Bank Annuals in Temporally Varying Environments. The American Naturalist, 127 (1), 31-47. doi:10.1086/284465

Cadman, C. S. C., Toorop, P. E., Hilhorst, H. W. M., \& Finch-Savage, W. E. (2006). Gene expression profiles of Arabidopsis Cvi seeds during dormancy cycling indicate a common underlying dormancy control mechanism. Plant Journal, 46 . doi:10.1111/j.1365-313X.2006.02738.x

Cao, Y., Xiao, Y., Huang, H., Xu, J., Hu, W., \& Wang, N. (2016). Simulated warming shifts the flowering phenology and sexual reproduction of Cardamine hirsuta under different planting densities.Scientific Reports, 6, 27835. doi:10.1038/srep27835

CaraDonna, P. J., Iler, A. M., \& Inouye, D. W. (2014). Shifts in flowering phenology reshape a subalpine plant community.Proceedings of the National Academy of Sciences, 111 (13), 4916-4921. doi:10.1073/pnas.1323073111

Cleland, E. E., Chuine, I., Menzel, A., Mooney, H. A., \& Schwartz, M. D. (2007). Shifting plant phenology in response to global change. Trends in Ecology $\& 3$ Evolution, 22 (7), 357-365.

Cochrane, A., Hoyle, G. L., Yates, C. J., Wood, J., \& Nicotra, A. B. (2015). The phenotypic response of co-occurring Banksia species to warming and drying. Plant Ecology, 216 (1), 27-39. doi:10.1007/s11258014-0414-z

Cochrane, A., Yates, C. J., Hoyle, G. L., \& Nicotra, A. B. (2015). Will among-population variation in seed traits improve the chance of species persistence under climate change? Global Ecology and Biogeography, 24 (1), 12-24. doi:10.1111/geb.12234

Debouk, H., de Bello, F., \& Sebastia, M.-T. (2015). Functional trait changes, productivity shifts and vegetation stability in mountain grasslands during a short-term warming. PLOS ONE, 10 (10), e0141899. doi:10.1371/journal.pone.0141899

Donat, M. G., \& Alexander, L. V. (2012). The shifting probability distribution of global daytime and night-time temperatures. Geophysical Research Letters, 39 (14), n/a-n/a. doi:10.1029/2012GL052459

Donohue, K. (1998). Maternal environmental effects in plants: Adaptive plasiticity. In T. A. Mousseau \& C. W. Fox (Eds.), Maternal Effects as Adaptations . New York: Oxford university press.

Donohue, K. (2009). Completing the cycle: Maternal effects as the missing link in plant life histories. Philosophical Transactions of the Royal Society of London B: Biological Sciences, 364 (1520), 1059-1074.

Donohue, K., de Casas, R. R., Burghardt, L., Kovach, K., \& Willis, C. G. (2010). Germination, postgermination adaptation, and species ecological ranges. Annual Review of Ecology and Systematics, 41 (1), 293-319. doi:DOI 10.1146/annurev-ecolsys-102209-144715

Donohue, K., Dorn, L., Griffith, C., Kim, E., Aguilera, A., Polisetty, C. R., \& Schmitt, J. (2005). The evolutionary ecology of seed germination of arabidopsis thaliana: Variable natural selection on germination timing. Evolution, 59 (4), 758-770. doi:10.1111/j.0014-3820.2005.tb01751.x

Dunnell, K. L., \& Travers, S. E. (2011). Shifts in the flowering phenology of the northern Great Plains: Patterns over 100 years.American Journal of Botany, 98 (6), 935-945. doi:10.3732/ajb.1000363

Easterling, D. R., Horton, B., Jones, P. D., Peterson, T. C., Karl, T. R., Parker, D. E., . . Folland, C. K. (1997). Maximum and minimum temperature trends for the globe. Science, 277 (5324), 364. 
Farnsworth, E. J., Nunez-Farfan, J., Careaga, S. A., \& Bazzaz, F. A. (1995). Phenology and growth of three temperate forest life forms in response to artificial soil warming. Journal of Ecology, 83 (6), 967-977. doi: $10.2307 / 2261178$

Footitt, S., \& Finch-Savage, W. E. (2017). Dormancy and Control of Seed Germination. In S. Clemens (Ed.), Plant Physiology and Function(pp. 1-30). New York, NY: Springer New York.

Franks, S. J., Sim, S., \& Weis, A. E. (2007). Rapid evolution of flowering time by an annual plant in response to a climate fluctuation.Proceedings of the National Academy of Sciences, 104 (4), 1278-1282. doi:10.1073/pnas.0608379104

Galloway, L. F. (2001a). The effect of maternal and paternal environments on seed characters in the herbaceous plant Campanula americana (Campanulaceae). American Journal of Botany, 88 (5), 832-840.

Galloway, L. F. (2001b). Parental environmental effects on life history in the herbaceous plant Campanula americana Ecology, 82 (10), 2781-2789. doi:10.1890/0012-9658(2001)082[2781:PEEOLH]2.0.CO;2

Galloway, L. F. (2005). Maternal effects provide phenotypic adaptation to local environmental conditions. New Phytologist, 166 (1), 93-100. doi:10.1111/j.1469-8137.2004.01314.x

Galloway, L. F., \& Etterson, J. R. (2007). Transgenerational plasticity is adaptive in the wild. Science, 318 . doi:10.1126/science.1148766

Geange, S. R., Briceno, V. F., Aitken, N. C., Ramirez-Valiente, J. A., Holloway-Phillips, M.-M., \& Nicotra, A. B. (2017). Phenotypic plasticity and water availability: responses of alpine herb species along an elevation gradient. Climate Change Responses, 4 (1), 5. doi:10.1186/s40665-017-0033-8

Geange, S. R., Holloway-Phillips, M.-M., Briceno, V. F., \& Nicotra, A. B. (2020). Aciphylla glacialis mortality, growth and frost resistance: a field warming experiment. Australian Journal of Botany , -. doi:https://doi.org/10.1071/BT19034

Grabherr, G., Gottfried, M., \& Pauli, H. (2010). Climate change impacts in alpine environments. Geography Compass, 4 (8), 1133-1153. doi:10.1111/j.1749-8198.2010.00356.x

Gutterman, Y. (2000). Maternal effects on seeds during development. In M. Fenner (Ed.), Seeds: The ecology of regeneration in plant communities (pp. 59-84). Wallingford, UK: CABI.

Hedhly, A., Hormaza, J. I., \& Herrero, M. (2009). Global warming and sexual plant reproduction. Trends in Plant Science, 14 (1), 30-36. doi:10.1016/j.tplants.2008.11.001

Hennessy, K., Whetton, P., Smith, I., Bathols, J., Hutchinson, M., \& Sharples, J. (2003). The impact of climate change on snow conditions in mainland Australia. Aspendale, Victoria: CSIRO Atmospheric Research.

Herman, J. J., \& Sultan, S. E. (2011). Adaptive transgenerational plasticity in plants: Case studies, mechanisms, and implications for natural populations. Frontiers in Plant Science, 2 , 102. doi:10.3389/fpls.2011.00102

Hoffmann, A. A., Camac, J. S., Williams, R. J., Papst, W., Jarrad, F. C., \& Wahren, C.-H. (2010). Phenological changes in six Australian subalpine plants in response to experimental warming and year-to-year variation. Journal of Ecology, 98 (4), 927-937. doi:10.1111/j.1365-2745.2010.01667.x

Hoffmann, A. A., \& Sgro, C. M. (2011). Climate change and evolutionary adaptation. Nature, 470 (7335), 479. doi:10.1038/nature09670

Hovenden, M. J., Newton, P. C. D., Wills, K. E., Janes, J. K., Williams, A. L., Vander Schoor, J. K., \& Nolan, M. J. (2008). Influence of warming on soil water potential controls seedling mortality in perennial but not annual species in a temperate grassland. New Phytologist, 180 (1), 143-152. doi:10.1111/j.14698137.2008.02563.x 
Hoyle, G., Cordiner, H., Good, R. B., \& Nicotra, A. B. (2014). Effects of reduced winter duration on seed dormancy and germination in six populations of the alpine herb Aciphyllya glacialis (Apiaceae).Conservation Physiology 2 (1), cou015-cou015. doi:10.1093/conphys/cou015

Hoyle, G., Steadman, K., Good, R., McIntosh, E., Galea, L., \& Nicotra, A. B. (2015). Seed germination strategies: An evolutionary trajectory independent of vegetative functional traits. Frontiers in Plant Science, 6 , 731. doi:10.3389/fpls.2015.00731

Hoyle, G. L., Steadman, K. J., Daws, M. I., \& Adkins, S. W. (2008). Pre- and post-harvest influences on seed dormancy status of an Australian Goodeniaceae species, Goodenia fascicularis .Annals of Botany, 102 (1), 93-101. doi:10.1093/aob/mcn062

Hoyle, G. L., Venn, S. E., Steadman, K. J., Good, R. B., McAuliffe, E. J., Williams, E. R., \& Nicotra, A. B. (2013). Soil warming increases plant species richness but decreases germination from the alpine soil seed bank. Global Change Biology, 19 (5), 1549-1561. doi:10.1111/gcb.12135

Huang, Z., Footitt, S., Tang, A., \& Finch-Savage, W. E. (2018). Predicted global warming scenarios impact on the mother plant to alter seed dormancy and germination behaviour in Arabidopsis. Plant, Cell $\mathcal{E}$ Environment, 41 (1), 187-197. doi:10.1111/pce.13082

Jin, B., Wang, L., Wang, J., Jiang, K.-Z., Wang, Y., Jiang, X.-X., . . . Teng, N.-J. (2011). The effect of experimental warming on leaf functional traits, leaf structure and leaf biochemistry in Arabidopsis thaliana. BMC plant biology, 11 , 35-35. doi:10.1186/1471-2229-11-35

Kimball, S., Angert, A. L., Huxman, T. E., \& Venable, D. L. (2010). Contemporary climate change in the Sonoran Desert favors cold-adapted species. Global Change Biology, 16 (5), 1555-1565. doi:10.1111/j.13652486.2009.02106.x

Kimball, S., Angert, A. L., Huxman, T. E., \& Venable, D. L. (2011). Differences in the timing of germination and reproduction relate to growth physiology and population dynamics of Sonoran Desert winter annuals. American Journal of Botany, 98 (11), 1773-1781. doi:10.3732/ajb.1100034

King, J. S., Pregitzer, K. S., \& Zak, D. R. (1999). Clonal variation in above-and below-ground growth responses of Populus tremuloidesMichaux: Influence of soil warming and nutrient availability.Plant and Soil, 217 (1-2), 119-130.

Korner, C. (2003). Alpine Plant Life: Functional Plant Ecology of High Mountain Ecosystems . New York; Berlin: Springer.

Korner, C., \& Basler, D. (2010). Phenology under global warming.Science, 327 (5972), 1461.

Kozłowski, J. (1992). Optimal allocation of resources to growth and reproduction: Implications for age and size at maturity. Trends in Ecology $\&$ Evolution, 7 (1), 15-19. doi:https://doi.org/10.1016/01695347(92)90192-E

Kudernatsch, T., Fischer, A., Bernhardt-Römermann, M., \& Abs, C. (2008). Short-term effects of temperature enhancement on growth and reproduction of alpine grassland species. Basic and Applied Ecology, 9 (3), 263-274.

Kudo, G., \& Suzuki, S. (2003). Warming effects on growth, production, and vegetation structure of alpine shrubs: a five-year experiment in northern Japan. Oecologia, 135 (2), 280-287.

Leblans, N. I. W., Sigurdsson, B. D., Vicca, S., Fu, Y., Penuelas, J., \& Janssens, I. A. (2017). Phenological responses of Icelandic subarctic grasslands to short-term and long-term natural soil warming. Global Change Biology, 23 (11), 4932-4945. doi:10.1111/gcb.13749

Lin, D., Xia, J., \& Wan, S. (2010). Climate warming and biomass accumulation of terrestrial plants: a meta-analysis. New Phytologist, 188 (1), 187-198. doi:10.1111/j.1469-8137.2010.03347.x 
Liu, Y., Mu, J., Niklas, K. J., Li, G., \& Sun, S. (2012). Global warming reduces plant reproductive output for temperate multi-inflorescence species on the Tibetan plateau. New Phytologist, 195 (2), 427-436. doi:10.1111/j.1469-8137.2012.04178.x

Lu, J. J., Tan, D. Y., Baskin, C. C., \& Baskin, J. M. (2016). Effects of germination season on life history traits and on transgenerational plasticity in seed dormancy in a cold desert annual. Scientific Reports, 6 , 25076. doi:10.1038/srep25076

Menzel, A., Sparks, T. H., Estrella, N., Koch, E., Aasa, A., Ahas, R., . . Z Zust, A. N. A. (2006). European phenological response to climate change matches the warming pattern. Global Change Biology, 12 (10), 1969-1976. doi:10.1111/j.1365-2486.2006.01193.x

Merilä, J., \& Hendry, A. P. (2014). Climate change, adaptation, and phenotypic plasticity: the problem and the evidence. Evolutionary Applications, 7 (1), 1-14. doi:10.1111/eva.12137

Milbau, A., Vandeplas, N., Kockelbergh, F., \& Nijs, I. (2017). Both seed germination and seedling mortality increase with experimental warming and fertilization in a subarctic tundra. AoB Plants, 9 (5), plx040-plx040. doi:10.1093/aobpla/plx040

Moore, L. M., \& Lauenroth, W. K. (2017). Differential effects of temperature and precipitation on early- vs. late-flowering species.Ecosphere, 8 (5), e01819. doi:10.1002/ecs2.1819

Munson, S. M., \& Sher, A. A. (2015). Long-term shifts in the phenology of rare and endemic Rocky Mountain plants. American Journal of Botany, 102 (8), 1268-1276. doi:10.3732/ajb.1500156

Nicotra, A. B., Atkin, O. K., Bonser, S. P., Davidson, A. M., Finnegan, E. J., Mathesius, U., . . . van Kleunen, M. (2010). Plant phenotypic plasticity in a changing climate. Trends in Plant Science, 15 (12), 684-692. doi:https://doi.org/10.1016/j.tplants.2010.09.008

Nicotra, A. B., Segal, D. L., Hoyle, G. L., Schrey, A. W., Verhoeven, K. J. F., \& Richards, C. L. (2015). Adaptive plasticity and epigenetic variation in response to warming in an Alpine plant. Ecology and Evolution, 5 (3), 634-647. doi:10.1002/ece3.1329

Nonogaki, H. (2017). Seed Biology Updates - Highlights and New Discoveries in Seed Dormancy and Germination Research. Frontiers in Plant Science, 8 (524). doi:10.3389/fpls.2017.00524

Oberbauer, S. F., Elmendorf, S. C., Troxler, T. G., Hollister, R. D., Rocha, A. V., Bret-Harte, M. S., . . . Welker, J. M. (2013). Phenological response of tundra plants to background climate variation tested using the International Tundra Experiment. Philosophical Transactions of the Royal Society B: Biological Sciences, 368 (1624).

Ooi, M. K. J., Auld, T. D., \& Denham, A. J. (2009). Climate change and bet-hedging: Interactions between increased soil temperatures and seed bank persistence. Global Change Biology, 15 (10), 2375-2386. doi:10.1111/j.1365-2486.2009.01887.x

Panetta, A. M., Stanton, M. L., \& Harte, J. (2018). Climate warming drives local extinction: Evidence from observation and experimentation.Science Advances, 4 (2), eaaq1819. doi:10.1126/sciadv.aaq1819

Parmesan, C., \& Hanley, M. E. (2015). Plants and climate change: Complexities and surprises. Annals of Botany, 116 (6), 849-864. doi:10.1093/aob/mcv169

Peñuelas, J., \& Filella, I. (2001). Responses to a warming world.Science, 294 (5543), 793.

Rathcke, B., \& Lacey, E. P. (1985). Phenological patterns of terrestrial plants. Annual Review of Ecology and Systematics, 16 (ArticleType: research-article / Full publication date: 1985 / Copyright (C) 1985 Annual Reviews), 179-214. doi:10.2307/2097047

Reinhardt, S., \& Odland, A. (2012). Soil temperature variation in calciphile mountain plant communities in Southern Norway. Oecologia Montana, 21, 21-35. 
Richards, C. L., Alonso, C., Becker, C., Bossdorf, O., Bucher, E., Colomé-Tatché, M., . . Verhoeven, K. J. F. (2017). Ecological plant epigenetics: Evidence from model and non-model species, and the way forward. Ecology Letters, 20 (12), 1576-1590. doi:10.1111/ele.12858

Roach, D. A., \& Wulff, R. D. (1987). Maternal Effects in Plants.Annual Review of Ecology and Systematics, 18 (1), 209-235. doi:10.1146/annurev.es.18.110187.001233

Root, T. L., Price, J. T., Hall, K. R., Schneider, S. H., Rosenzweig, C., \& Pounds, J. A. (2003). Fingerprints of global warming on wild animals and plants. Nature, 421 (6918), 57-60. doi:http://www.nature.com/nature/journal/v421/n6918/suppinfo/nature01333_S1.html

Saatkamp, A., Cochrane, A., Commander, L., Guja, Lydia K., Jimenez-Alfaro, B., Larson, J., . . Walck, J. L. (2018). A research agenda for seed-trait functional ecology. New Phytologist, 0 (0). doi:10.1111/nph.15502

Satyanti, A. (2018). A multi-scale exploration of the drivers and implications of germination strategy in Australian alpine plants.(PhD), The Australian National University, Canberra.

Satyanti, A., Guja, L. K., \& Nicotra, A. B. (2019). Temperature variability drives within-species variation in germination strategy and establishment characteristics of an alpine herb. Oecologia . doi:10.1007/s00442018-04328-2

Scherrer, D., Schmid, S., \& Körner, C. (2011). Elevational species shifts in a warmer climate are overestimated when based on weather station data. International Journal of Biometeorology, 55 (4), 645-654. doi:10.1007/s00484-010-0364-7

Schneider, C. A., Rasband, W. S., \& Eliceiri, K. W. (2012). NIH Image to ImageJ: 25 years of image analysis. Nature Methods, 9 (7), 671-675.

Schütz, W. (2000). Ecology of seed dormancy and germination in sedges (Carex). Perspectives in Plant Ecology, Evolution and Systematics, 3 (1), 67-89. doi:10.1078/1433-8319-00005

Schütz, W., \& Milberg, P. (1997). Seed dormancy in Carex canescens : Regional differences and ecological consequences.Oikos, 78 (3), 420-428. doi:10.2307/3545604

Sherry, R. A., Zhou, X. H., Gu, S. L., Arnone, J. A., Schimel, D. S., Verburg, P. S., . . Luo, Y. Q. (2007). Divergence of reproductive phenology under climate warming. Proceedings of the National Academy of Sciences of the United States of America, 104 (1), 198-202. doi:10.1073/pnas.0605642104

Simons Andrew, M. (2009). Fluctuating natural selection accounts for the evolution of diversification bet hedging. Proceedings of the Royal Society B: Biological Sciences, 276 (1664), 1987-1992. doi:10.1098/rspb.2008.1920

Slatyer, R. A. (2016). Geographic Range and the Mountain Niche: Ecology, Adaptation and Environmental Change. (PhD), The University of Melbourne, Melbourne.

Springate, D. A., \& Kover, P. X. (2014). Plant responses to elevated temperatures: a field study on phenological sensitivity and fitness responses to simulated climate warming. Global Change Biology, 20 (2), 456-465. doi:10.1111/gcb.12430

Starr, G. R. e., Oberbauer, S. F., \& Pop, E. R. I. C. W. (2000). Effects of lengthened growing season and soil warming on the phenology and physiology of Polygonum bistorta. Global Change Biology, 6 (3), 357-369. doi:10.1046/j.1365-2486.2000.00316.x

Starrfelt, J., \& Kokko, H. (2012). Bet-hedging a triple trade-off between means, variances and correlations. Biological Reviews, 87 (3), 742-755. doi:10.1111/j.1469-185X.2012.00225.x

Steadman, K. J., Ellery, A. J., Chapman, R., Moore, A., \& Turner, N. C. (2004). Maturation temperature and rainfall influence seed dormancy characteristics of annual ryegrass (Lolium rigidum). Australian Journal of Agricultural Research, 55 (10), 1047-1057. doi:https://doi.org/10.1071/AR04083 
Stevens, N., Seal, C. E., Archibald, S., \& Bond, W. (2014). Increasing temperatures can improve seedling establishment in arid-adapted savanna trees. Oecologia, 175 (3), 1029-1040. doi:10.1007/s00442-014-2958-y

Stinson, K. A. (2004). Natural selection favors rapid reproductive phenology in Potentilla pulcherrima (Rosaceae) at opposite ends of a subalpine snowmelt gradient. American Journal of Botany, 91 (4), 531539.

Topham, A. T., Taylor, R. E., Yan, D., Nambara, E., Johnston, I. G., \& Bassel, G. W. (2017). Temperature variability is integrated by a spatially embedded decision-making center to break dormancy in \&lt;em\&gt;Arabidopsis\&lt;/em\&gt; seeds. Proceedings of the National Academy of Sciences, 114 (25), 6629. doi:10.1073/pnas.1704745114

Valdes, A., Marteinsdottir, B., \& Ehrlen, J. (2019). A natural heating experiment: Phenotypic and genotypic responses of plant phenology to geothermal soil warming. Global Change Biology, 25 (3), 954-962. doi:10.1111/gcb.14525

Venable, D. L., \& Brown, J. S. (1988). The selective interactions of dispersal, dormancy, and seed size as adaptations for reducing risk in variable environments. The American Naturalist, 131 (3), 360-384.

Venable, D. L., \& Lawlor, L. (1980). Delayed germination and dispersal in desert annuals: Escape in space and time. Oecologia, 46 (2), 272-282. doi:10.1007/BF00540137

Vidigal, D. S., Marques, A. C. S. S., Willems, L. A. J., Buijs, G., Mendez-Vigo, B., Hilhorst, H. W. M., . . . Alonso-Blanco, C. (2016). Altitudinal and climatic associations of seed dormancy and flowering traits evidence adaptation of annual life cycle timing in Arabidopsis thaliana. Plant, Cell ES Environment, 39 (8), 1737-1748. doi:10.1111/pce.12734

Visser, M. E., \& Both, C. (2005). Shifts in phenology due to global climate change: the need for a yardstick. Proceedings of the Royal Society B: Biological Sciences, 272 (1581), 2561-2569. doi:10.1098/rspb.2005.3356

Wagner, I., \& Simons, A. M. (2009). Intraspecific divergence in seed germination traits between highand low-latitude populations of the arctic-alpine annual Koenigia islandica . Arctic, Antarctic, and Alpine Research, 40 (1), 233-239. doi:10.1657/1523-0430\%2807-003\%29\%5bwagner\%5d2.0.co\%3b2

Walker, M. D., Wahren, C. H., Hollister, R. D., Henry, G. H. R., Ahlquist, L. E., Alatalo, J. M., . . . Wookey, P. A. (2006). Plant community responses to experimental warming across the tundra biome.Proceedings of the National Academy of Sciences, 103 (5), 1342. doi:10.1073/pnas.0503198103

Walther, G.-R., Post, E., Convey, P., Menzel, A., Parmesan, C., Beebee, T. J. C., . . . Bairlein, F. (2002). Ecological responses to recent climate change. Nature, 416 (6879), 389-395.

Willis, C. G., Baskin, C. C., Baskin, J. M., Auld, J. R., Venable, D. L., Cavender-Bares, J., . . The, N. G. W. G. (2014). The evolution of seed dormancy: environmental cues, evolutionary hubs, and diversification of the seed plants. New Phytologist, 203 (1), 300-309. doi:10.1111/nph.12782

Willis, C. G., Ruhfel, B., Primack, R. B., Miller-Rushing, A. J., \& Davis, C. C. (2008). Phylogenetic patterns of species loss in Thoreau's woods are driven by climate change. Proceedings of the National Academy of Sciences, 105 (44), 17029-17033. doi:10.1073/pnas.0806446105

Wolkovich, E. M., Cook, B. I., Allen, J. M., Crimmins, T. M., Betancourt, J. L., Travers, S. E., . . . Cleland, E. E. (2012). Warming experiments underpredict plant phenological responses to climate change.Nature, 485 (7399), 494-497. doi:http://www.nature.com/nature/journal/v485/n7399/abs/nature11014.html\#supplementaryinformation 


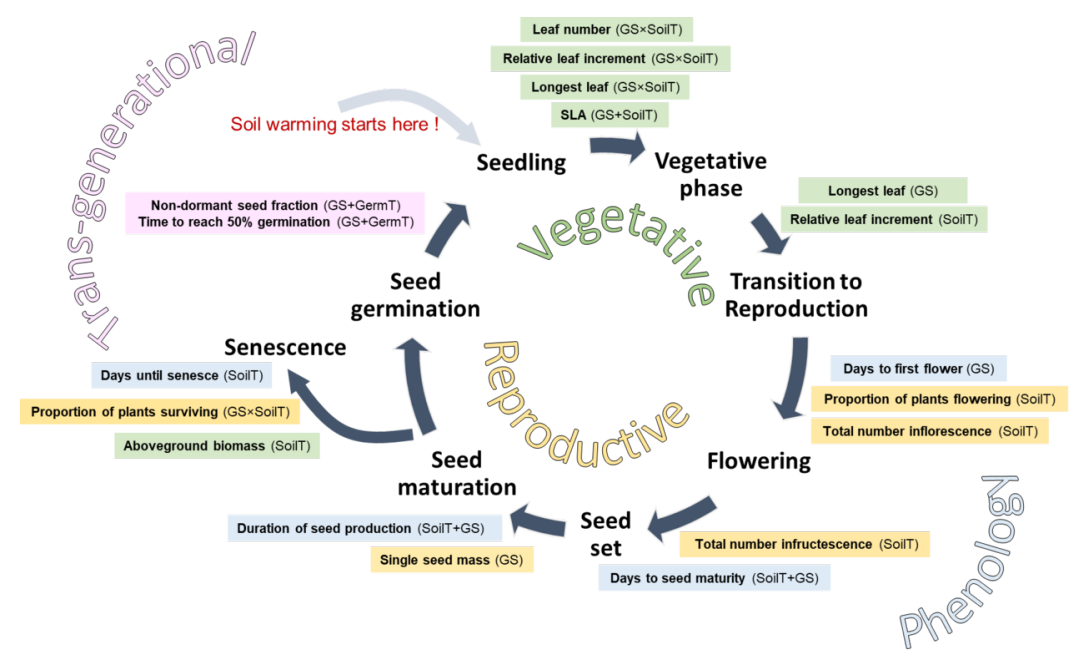

Fig. 1 The life cycle of Oreomyrrhis eriopoda from early vegetative growth to reproduction and senescence. Of 19 traits measured, 16 traits were influenced by experimental factors: germination strategy (GS), development temperature (SoilT), or their interactions $(\mathrm{GS} \times \mathrm{SoilT})$, at some stage. Transgenerational seed traits were only affected by germination temperature (GermT) and not maternal SoilT. Box colours indicate traits: vegetative (pale green), reproductive (pale yellow), phenology (pale blue), and the trans-generational effect on seed germination (pink). Significant fixed terms are given in brackets; detailed results are presented in Table 1, Table 2, Fig. 2 to 4, and Table S2 and S3.
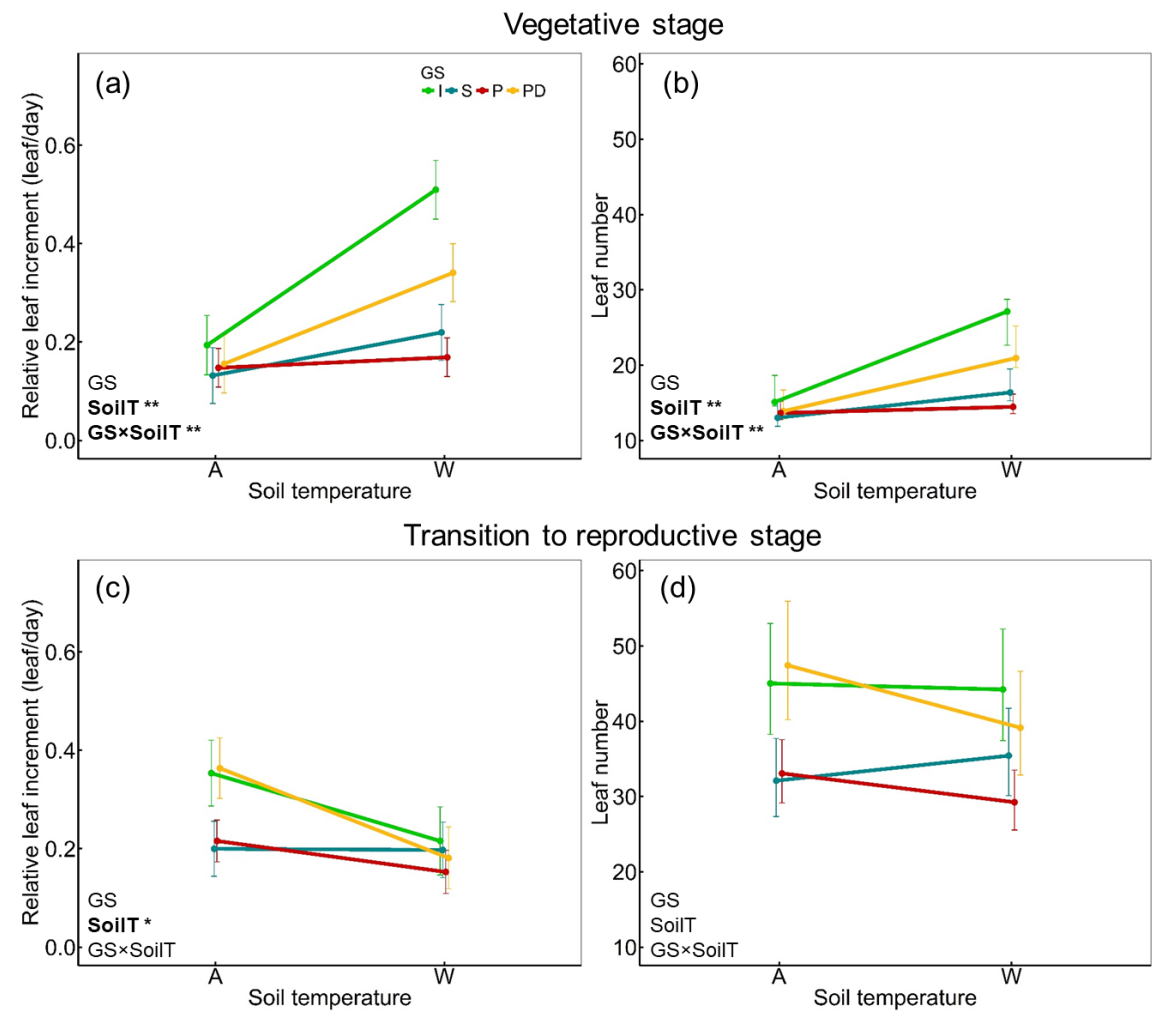
Fig. 2 Vegetative growth under developmental soil temperature (SoilT, x-axis) across germination strategies (GS) indicated by the mean \pm SE: a) Relative leaf increment and b) Absolute leaf number at vegetative stage, c) Relative leaf increment, and d) Absolute leaf number at the transition to reproductive stage. At the early vegetative stage, the effects of germination strategy and soil temperature were more pronounced than at the transition to reproduction. Significant terms are indicated by the bolded term and asterisk; * $=$ significant at $\mathrm{p}<0.05,{ }^{* *}=$ significant at $\mathrm{p}<0.001$. Line colour represents germination strategy (GS): green (I: immediate), blue (S: staggered), red (P: postponed), yellow (PD: postponed-deep).
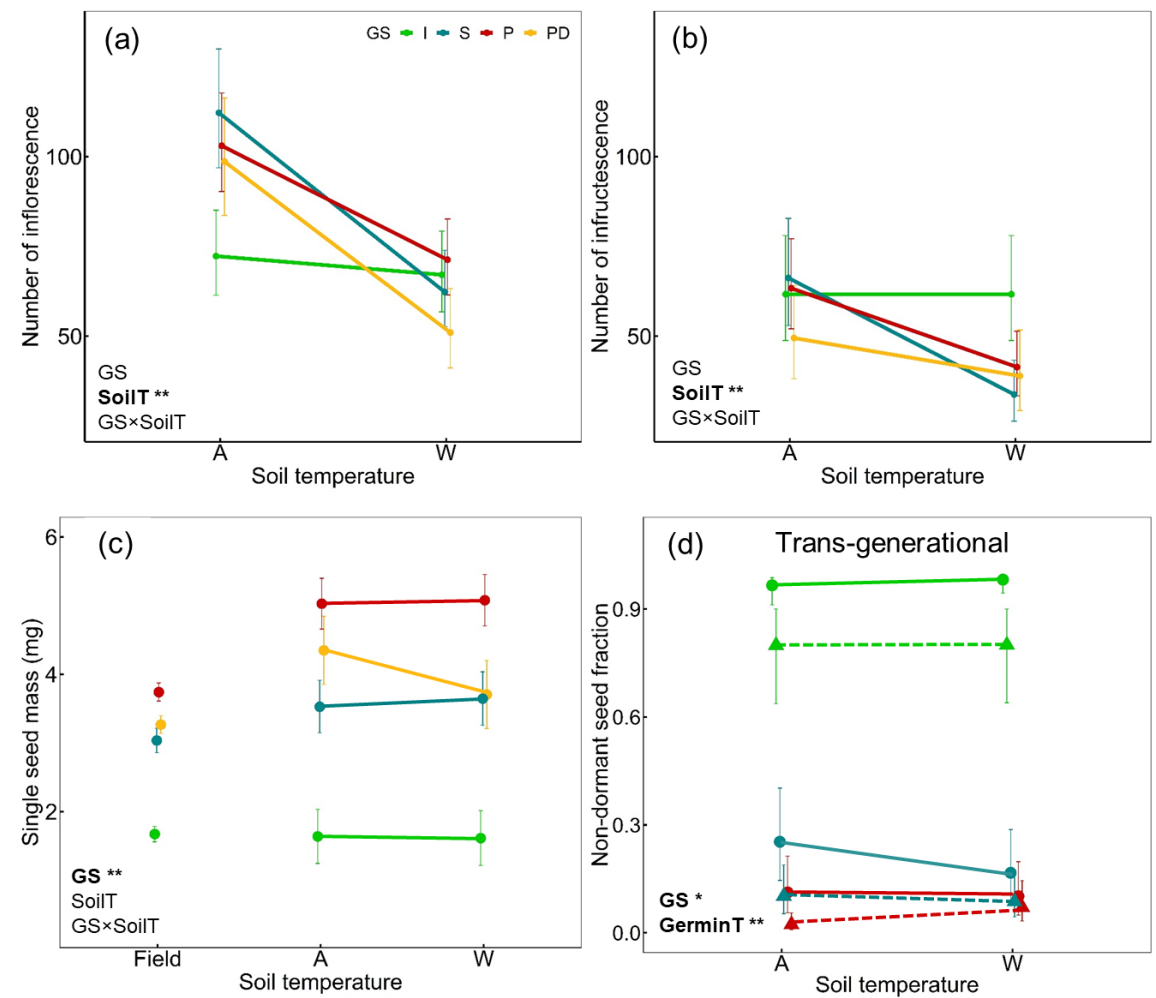

Fig. 3 The effect of developmental soil temperature (SoilT, x-axis) and germination strategy (GS) on reproductive stage across germination strategy indicated by mean \pm SE: a) Soil warming reduced the total number of inflorescences produced by an individual for all except the immediate strategy, b) Soil warming reduced the total number of infructescence produced by an individual for all except the immediate strategy, and c) Seed mass differed among GS and seeds produced in the experiment had larger seeds than the field-collected seed (mother plant). Trans-generational stage d) Non-dormant seed fraction (autumn germination) was higher when seeds germinated at $25 / 15{ }^{\circ} \mathrm{C}$ (*- full line) than at 30/20 $\operatorname{deg} \mathrm{C}\left({ }^{-}-{ }_{-}-\right.$dashedline); GSwasconservedasindicatedbythenon significanteffectof soilwarming. Forthetransgenerationalstage, wherewehadGS, maternalsoiltemperature, andgerminat $\operatorname{green}(I \quad: \quad$ immediate $), \operatorname{blue}(S \quad: \quad$ staggered $), \operatorname{red}(P \quad: \quad$ postponed $)$,yellow $(P D \quad: \quad$ postponed deep).Significancevaluesareindicatedbyboldedtermsandasterisk $*=$ significantatp $<0.05, * *=$ significantatp $<0.001$.

Fig. 4 The reproductive phenology and senescence indicated by the coloured bar of the events: day to first flower emergence, day to first seed maturation from flowering, the duration of seed production - first to last seed maturation, and senescence from the last seed maturation. Numbers in white font (left) indicate 
the proportion of plants flowering and in black font (right) indicate the proportion of plants surviving. In the legend, bolded terms, i.e. developmental soil temperature, (SoilT) and germination strategy (GS) and asterisks indicate significance (Table 1, Table S2).

Table 1 Significance values for selected vegetative, reproductive and phenology traits analyses; full details in Supplement Table S2. Mixed models were used in which germination strategy (GS), i.e. Immediate (I), Staggered (S), Postponed (P), Postponed-deep (PD), and Soil Temperature (SoilT), i.e. Ambient (A) and Warm (W), were assigned as the fixed factors and population nested in block as random factor. Where appropriate, leaf number at the start of the experiment was added as a covariate in the analysis in addition to block/population $(++)$.

\begin{tabular}{|c|c|c|c|c|c|c|}
\hline Response & GS & GS & SoilT & SoilT & GS $\times$ SoilT & GS $\times$ Soil $^{r}$ \\
\hline \multicolumn{7}{|l|}{ Early vegetative stage } \\
\hline Leaf number ++ & 0.063 & & $<0.001$ & $\mathbf{A}<\mathbf{W}$ & $<0.001$ & $\mathbf{I}(\mathbf{A}<\mathbf{W})$ \\
\hline Relative leaf increment (leaf per day) ++ & 0.063 & & $<0.001$ & $\mathbf{A}<\mathbf{W}$ & $<0.001$ & $\mathbf{I}(\mathbf{A}<\mathbf{W})$ \\
\hline Longest leaf & $<0.001$ & $\mathbf{I}<\mathbf{S}<\mathbf{P D}<\mathbf{P}$ & 0.626 & & 0.043 & $\mathbf{I}(\mathbf{A}>\mathbf{W})$ \\
\hline Specific Leaf Area $\left(\mathrm{cm}^{2} \mathrm{~g}^{-1}\right)$ & 0.041 & $\mathbf{P}<(\mathbf{I}, \mathbf{S}, \mathbf{P D})$ & $<0.001$ & $\mathbf{A}<\mathbf{W}$ & 0.903 & \\
\hline \multicolumn{7}{|l|}{ Transition to reproductive stage } \\
\hline Leaf number ++ & 0.208 & & 0.363 & & 0.533 & \\
\hline Relative leaf increment (leaf per day) ++ & 0.417 & & 0.004 & $\mathbf{A}>\mathbf{W}$ & 0.179 & \\
\hline Longest leaf & 0.043 & $\mathbf{I}<(\mathbf{S}, \mathbf{P}, \mathbf{P D})$ & 0.793 & & 0.963 & \\
\hline Canopy area $\left(\mathrm{cm}^{2}\right)++$ & 0.458 & & 0.875 & & 0.333 & \\
\hline \multicolumn{7}{|l|}{ Reproduction stage } \\
\hline Proportion of plants flowering & 0.189 & & 0.028 & $\mathbf{A}>\mathbf{W}$ & 0.079 & \\
\hline Total number of inflorescence & 0.143 & & $<0.001$ & $\mathbf{A}>\mathbf{W}$ & 0.094 & \\
\hline Total number of infructescence & 0.260 & & $<0.001$ & $\mathbf{A}>\mathbf{W}$ & 0.094 & \\
\hline Single seed mass & $<0.001$ & $\mathbf{I}<(\mathbf{S}, \mathbf{P D})<\mathbf{P}$ & 0.527 & & 0.174 & \\
\hline \multicolumn{7}{|l|}{ Phenology } \\
\hline Days to first flower & $<0.001$ & $\mathbf{I}<(\mathbf{S}, \mathbf{P}, \mathbf{P D})$ & 0.645 & & 0.238 & 0.238 \\
\hline Days to seed maturity from flowering & $<0.001$ & $\mathbf{I}>(\mathbf{S}, \mathbf{P}, \mathbf{P D})$ & 0.002 & $\mathbf{A}>\mathbf{W}$ & 0.139 & 0.139 \\
\hline Duration of seed production & $<0.001$ & $\mathbf{I}>(\mathbf{S}, \mathbf{P}, \mathbf{P D})$ & 0.007 & $\mathbf{A}>\mathbf{W}$ & 0.312 & 0.312 \\
\hline Days to plant death from planting & 0.614 & & $<0.001$ & $\mathbf{A}>\mathbf{W}$ & 0.091 & 0.091 \\
\hline \multicolumn{7}{|l|}{ Final survival and aboveground biomass } \\
\hline Proportion of plants surviving & 0.214 & & 0.008 & $\mathbf{A}>\mathbf{W}$ & 0.008 & 0.008 \\
\hline Aboveground biomass ++ & 0.695 & & 0.019 & $\mathbf{A}>\mathbf{W}$ & 0.399 & 0.399 \\
\hline
\end{tabular}

Table 2 Significance values of transgenerational effects on germination strategy. Germination strategy (GS), maternal soil temperature (SoilT), and Germination Temperature (GermT) were assigned as fixed factors, with individual nested in population and shelf blocking as random factor. Generalized Linear Mixed Models were used to analyse the proportion of non-dormant seed fraction and final germination. A Linear Mixed Model was used to analyse the time to reach $50 \%$ of germination. The germination strategy (GS) is abbreviated as Immediate (I), Staggered (S), Postponed (P), Postponed-deep (PD), and Soil Temperature (SoilT), i.e. Ambient (A) and Warm (W), were assigned as the fixed factors and population nested in block as random factor. Details in Table S3.

\begin{tabular}{lllllll}
\hline Transgenerational seed germination responses & GS & GS & SoilT & GermT & GermT & GS $\times$ SoilT \\
\hline Non-dormant seed fraction & $\mathbf{0 . 0 1 2}$ & $\mathbf{I}>\mathbf{S}>\mathbf{P}$ & 0.347 & $<\mathbf{0 . 0 0 1}$ & $\mathbf{A}>\mathbf{W}$ & 0.318 \\
Time to reach 50\% of seed germination & $<\mathbf{0 . 0 0 1}$ & $\mathbf{I}<\mathbf{S}=\mathbf{P})$ & 0.461 & $<\mathbf{0 . 0 0 1}$ & $\mathbf{A}<\mathbf{W}$ & 0.227 \\
Final germination & 0.092 & & 0.849 & 0.067 & & 0.603 \\
\hline
\end{tabular}




\section{Supporting Information}

Appendix 1. Germination and seedling transplant methods

Supplementary Figure 1. The detailed population and germination strategy allocations across blocks with the targeted temperature regime and the seasons. Population names are coloured based on germination strategy and followed by seedling germination season if two germination timings occurred within a population. Germination strategies were: Immediate (I), Staggered (S), Postponed (P), and Postponed-deep (PD); autumn (early) germinating seed was coded as '(/au)' and spring (late) germinating seed as '(/sp)'. Where plant availability was low, extra pots were placed into the experiment to ensure equivalent neighbour effects for all pots. Those extras were not part of the analysis and the pots are shown with grey labels. Red asterisks indicate individuals from which seed was sourced for the trans-generational experiment. Each pot contained one plant. Pots with orange pin (without plant; pot number 83, 93, 182, 192, 263, 278, 441 and 451) were the pots allocated for i-Buttons ( 3 i-Buttons below the soil and 1 i-Button above the soil) in each block.

Supplementary Figure 2. The realised mean temperature in ambient and warm conditions during the day at a) plant level $15 \mathrm{~cm}$ above the pot, and b) $8 \mathrm{~cm}$ below the soil surface; and during the night, c) plant level $15 \mathrm{~cm}$ above the pot, and d) $8 \mathrm{~cm}$ below the soil surface. At each season, warm conditions were significantly warmer than ambient $(\mathrm{p}<0.001$, ANOVA). Note: data loggers for plant level temperatures were only started in winter. The boxes along the bottom of the figure indicate the target soil temperatures for ambient (A) and warm (W) treatment for each season.

Supplementary Figure 3. Offspring germination of the staggered strategy under ambient germination temperature over time (indicated by x-axis). Lines indicate which individual (mother plant) produced the seeds; each line represents 100 seeds. Line colour and style indicate maternal soil temperature - solid blue for ambient soils and dashed orange for warmer soil temperatures.

Supplementary Table 1 . The distribution of population and germination strategies (GS) across the blocks: Immediate (I), Staggered (S), Postponed (P), and Postponed-deep (PD). Population name reflects the collection sites: Namadgi (Nam), Kosciuszko (Kos), Victoria (Vic), and Tasmania (Tas). Seeds for each population were bulk sampled from multiple plants. There was imbalance in the distribution of germination strategies across blocks, but this was not so extensive as to be an impediment to statistical analyses. Accessions with grey font are those re-determined as other Oreomyrrhis species, new species ID in bracket, and thus were excluded in the analyses.

Supplementary Table 2. Significance of the germination strategy (GS) and warming (SoilT) on the vegetative, reproductive traits, and phenology. Generalized Linear Mixed model and Linear Mixed Model were used to analyse the data with fixed term as GS $\times$ SoilT. The random term was population nested in block (block/pop). Plant area and aboveground biomass were transformed using natural logarithms. In the direction column, GS are noted as Immediate (I), Staggered (S), Postponed (P), and Postponed-deep (PD) and SoilT are as Ambient (A) and Warm (W).

Table S3. Transgenerational effects on germination traits. The significance of germination strategy (GS), soil temperature (SoilT), and germination temperature (GermT). The analyses were performed using mixed models with $\mathrm{GS} \times$ SoilT $\times$ GermT as fixed and population and individual plant nested in shelf as random factors. 